\title{
Repúblicas laicas en Europa y América: la separación de la Iglesia y el Estado en Portugal vista desde México, 1910 - 1913*
}

\section{Resumen}

En este artículo se presenta un análisis de la relación bilateral entre México y Portugal, en el periodo de 1910 a 1913, a partir de un caso concreto: las reacciones que produjo en México la proclamación de la República Portuguesa y, posteriormente, la noticia de la separación Iglesia-Estado en abril de 1911. En el análisis se evidencia que el gobierno mexicano, con base en la información enviada por el poeta y diplomático Balbino Dávalos encargado de negocios de México en Lisboa, tuvo una reacción ambivalente ante la instauración del régimen republicano y la laicidad del Estado portugués. Por una parte, se aceptó y se apoyó el cambio de sistema de gobierno, pues algunos consideraron que esta medida permitiría estrechar la relación entre ambas naciones, al compartir el mismo régimen político y una misma relación frente a la Iglesia. De otro lado, en los círculos diplomáticos y en las elites locales, la caída de la monarquía fue asumida como una interrupción a la paz, el orden y la estabilidad, similar a la Revolución Mexicana que entre 1910 y 1911 provocó el fin del régimen de Porfirio Díaz y el inicio del gobierno de Francisco León de la Barra y Francisco I. Madero.

Palabras clave: México, Portugal, diplomacia, república, anticlericalismo, revolución.

Referencia para citar este artículo: ROSAS SALAS, Francisco (2015). "Repúblicas laicas en Europa y América: la separación de la Iglesia y el Estado en Portugal vista desde México, 1910-1913”. En Anuario de Historia Regional y de las Fronteras. 20 (2). pp. 271-292.

Sergio Francisco Rosas Salas: Doctor y Maestro en Ciencias Humanas por El Colegio de Michoacán. Licenciado en Historia de la Benemérita Universidad Autónoma de Puebla. Profesor Investigador del Área de Historia, Instituto de Ciencias Sociales y Humanidades “Alfonso Vélez Pliego" y de la Benemérita Universidad Autónoma de Puebla. Correo electrónico: sergiofrosas@yahoo.com.mx; rosass@colmich.edu.mx.

\footnotetext{
* Artículo de investigación científica elaborado en el marco del proyecto "Las relaciones diplomáticas entre Europa y Portugal en la época contemporánea”. Contó con los recursos del Consejo Nacional para la Ciencia y la Tecnología (Conacyt) a través de las Becas Mixtas para estudios de Doctorado; además, con el apoyo financiero y respaldo institucional del Centro de Estudos de História Religiosa de la Universidad Católica Portuguesa.
} 


\title{
Secular republics in Europe and America: the Portuguese separation law as seen from Mexico, 1910 - 1913
}

\begin{abstract}
This article aims to analyze the bilateral relationship between Mexico and Portugal between 1910 and 1913 on the basis of a concrete case: reconstructing the reactions produced in Mexico by the declaration of the Portuguese Republic and, later on, the announcement of the Church-State separation, in April 1911, which was one of the core aspects of the Portuguese republican movement. It proves that the Mexican government, based on the information sent by the poet and diplomat, Balbino Davalos, who was in charge of Mexico's businesses in Lisbon, had an ambivalent reaction towards the onset of the republican regime, and the secularization of the Portuguese state. On one hand, the change of government system was accepted and even supported, for they considered this measure would allow strengthening the relationship between both nations, since they share the same political regime and the same relationship with the Church. On the other hand, specially within the diplomatic circles and local elites, the fall of the monarchy was considered a disruption of peace, order and stability similar to that one of the Mexican revolution, that led to the end of Porfirio Diaz's regime between 1910 and 1911; and the beginning of Francisco y Madero's government.
\end{abstract}

Keywords: Mexico, Portugal, diplomacy, republic, anticlericalism, revolution.

\section{Repúblicas laicas na Europa e América: a lei de separação Portuguesa vista desde o México, 1910 - 1913}

\section{Resumo}

O artigo tem como objetivo analisar a relação bilateral entre o México e Portugal entre 1910 e 1913 a partir de um caso concreto: reconstruir as reações que produziu no México a proclamação da República Portuguesa e, mais adiante, a noticia da separação da Igreja - Estado, em abril de 1911, um dos aspectos centrais do movimento republicano português. Demonstra que o governo mexicano, com base na informação enviada pelo poeta e diplomático Balbino Dávalos, encarregado de negócios do México em Lisboa, teve uma reação ambivalente diante da instauração do regime republicano e a laicização do Estado português. Por um lado, aceitou e inclusive apoiou a mudança do sistema de governo, pois consideraram que esta medida permitiria estreitar a relação entre ambas nações, ao compartilhar o mesmo regime político e uma mesma relação diante da Igreja. Por outro lado, principalmente nos círculos diplomáticos e nas elites locais, a queda da monarquia foi considerada uma interrupção da paz, a ordem e a estabilidade, similar à revolução mexicana, que entre 1910 e 1911 provocou o fim do regime de Porfirio Díaz e o começo do governo de Francisco Madero.

Palavras-chave: México, Portugal, a diplomacia, república, anticlericalismo, revolução. 


\section{Introducción}

El objetivo de este artículo es analizar la relación bilateral de México y Portugal, entre 1910 y 1913, sobre un aspecto concreto: las reacciones que produjo en México la proclamación de la República Portuguesa y, en una segunda instancia, la separación Iglesia-Estado decretada en Lisboa en abril de 1911, uno de los aspectos centrales del movimiento republicano lusitano. El análisis busca evidenciar que con base en la información enviada por el diplomático y poeta Balbino Dávalos, encargado de negocios de México en Lisboa, el gobierno mexicano tuvo una reacción positiva ante la instauración del régimen republicano y la ley de separación de Iglesia y Estado decretada por la República Portuguesa. En México se aceptó e incluso apoyó el cambio de régimen, pues los actores políticos de aquel país consideraron que esta medida permitiría estrechar la relación entre las dos naciones, al compartir el mismo sistema político y una base jurídica común frente a la Iglesia católica y, más ampliamente, frente a la religión en ambas sociedades. Así, uno de los aspectos que este artículo subraya es que la historia de ambos países revela que en los primeros años del siglo XX la república estaba asociada a la implementación de las políticas liberales en los países mayoritariamente católicos. De hecho, en aquel periodo, la república era considerada esencialmente anticlerical, pues las medidas secularizadoras fueron parte básica de la constitución de esta como régimen político. Mientras en Portugal la separación entre Iglesia y Estado, concretada gracias a la revolución de 1910, estuvo íntimamente ligada a las aspiraciones de los intelectuales liberales; en México, el liberalismo dejó de ser una ideología en lucha desde el fin de la Reforma y se convirtió en un mito unificador de los actores políticos e intelectuales a partir de $1867^{1}$. Un elemento central del régimen liberal mexicano fue la independencia entre Iglesia y Estado, decretada por el presidente Benito Juárez en julio de 1859; por otra parte, la separación de ambas esferas fue aplicada en Portugal, como se dijo, en abril de 1911.

La disociación jurídica entre Iglesia y Estado es parte de un proceso que la historiografía y la teoría política han caracterizado como laicidad. En términos generales, la laicidad es el reconocimiento legal, por parte de los Estados, de la pluralidad religiosa existente en las sociedades contemporáneas, y puede considerarse grosso modo como un principio legal y político que sostiene la neutralidad del Estado en materia religiosa, en aras de la defensa -dentro del derecho público- de la consciencia, la libertad y la verdad individual. Desde esta perspectiva, la laicidad es un proceso de regulación jurídica y de institucionalización de un régimen ajeno a lo religioso que hace posible el ejercicio de cualquier culto por parte de los ciudadanos de un país, en el entendido de que la fe pertenece a la consciencia de cada ciudadano. Vista así, la laicidad no implica una antinomia de lo religioso, sino más bien una afirmación del Estado contemporáneo en sociedades de tradición mayoritariamente católica; es la expresión legal de la ausencia del confesionalismo por parte del poder civil y la búsqueda de una legitimidad política más allá de lo religioso ${ }^{2}$. En suma, la laicidad

\footnotetext{
${ }^{1}$ HALE, Charles, The transformation of liberalism in late Nineteenth-century Mexico, Princeton, Princeton University Press, 1989, pp. 9-10.

${ }^{2}$ POULAT, Émile, Liberté, laicieté: la guerre des deux France et le principe de la modernité, Paris,
} 
forma parte, como su expresión legal, del más amplio proceso de secularización, el cual es un proceso de ruptura de larga duración en el mundo occidental, en cuya base está el surgimiento del individuo y el Estado a partir de la separación de las esferas religiosa y secular -imbricadas en el Antiguo Régimen-. Su objetivo es construir una soberanía basada en la voluntad de los ciudadanos que resultará, en última instancia, en el surgimiento de una esfera pública secular ${ }^{3}$.

A partir de estos presupuestos, estas líneas muestran que los procesos políticos de ambos lados del Atlántico seguían ritmos similares. En últimas, subrayar la simultaneidad de los cambios sociales en Europa y América puede ser una valiosa invitación para reflexionar sobre las historias comparadas entre los distintos países de estos continentes, y para repensar las relaciones culturales, políticas y sociales entre los países de raigambre católica y liberal. Pensar comparativamente, por ejemplo, posibilita percatarse como en Francia la ley de separación data de 1905, y la constitución política de México de 1917 insiste en medidas abiertamente anticlericales de separación entre Iglesia y Estado. Por tanto, este artículo quiere llamar la atención sobre la necesidad de pensar globalmente los problemas históricos para comprender procesos globales, por fuera de las fronteras nacionales.

Por otra parte, el caso analizado muestra que sobre todo en los círculos diplomáticos y en las elites locales, la caída de la monarquía fue considerada una interrupción a la paz, el orden y la estabilidad, semejante a la Revolución Mexicana que a lo largo de 1910 y 1911 bajo el mando de Francisco I. Madero, provocó el fin del régimen de Porfirio Díaz, quien había gobernado el país por más de treinta años, entre 1876 y $1911^{4}$.

Les Éditions du Cerf, Editions Cujas, 1987; POULAT, Émile, La solution laique et ses problemes. Fausses certitudes, vrais inconnues, Paris, Berg International Editeurs, 1999; MATOS FERREIRA, António, Um católico militante diante da crise nacional. Manuel Isaías Abúndio da Silva (1874-1914), Lisboa, Universidade Católica Portuguesa, Centro de Estudos de História Religiosa, 2007; BARBOSA DELGADO, Francisco Roberto, "El principio de laicidad en la educación en Francia y en el tribunal Europeo de Derechos Humanos: entre el universalismo francés y el reconocimiento al margen nacional de apreciación del TEDH", en Oasis, No. 16, 2011, pp. 39-58; MALLIMACI, Fortunato, "Catolicismo y liberalismo: las etapas del enfrentamiento por la definición de la modernidad religiosa en América Latina", en BASTIAN, Jean-Pierre (Coord.), La modernidad religiosa. Europa y América latina en perspectiva comparada, México, Fondo de Cultura Económica, 2004, pp. 19-44; DE ROUX, Rodolfo, "Las etapas de la laicización en Colombia", en BASTIAN, Jean-Pierre (Coord.), La modernidad religiosa. Europa y América latina en perspectiva comparada, México, Fondo de Cultura Económica, 2004, pp. 61-73; RIBEIRO PINTO, Sérgio, Separaçao Religiosa como Modernidade. Decreto-Lei 20 de Abril de 1911 e modelos alternativos, Lisboa, Universidade Católica Portuguesa, 2011; BLANCARTE, Roberto, Laicidad en México, México, Universidad Nacional Autónoma de México, Cátedra Extraordinaria Benito Juárez, Instituto de Investigaciones Jurídicas, 2013.

${ }^{3}$ MATOS FERREIRA, "Laicidade", en MOREIRA AZEVEDO, Carlos (Dir.), Diccionário de História Religiosa de Portugal, Lisboa, Círculo de Leitores, 2001, pp. 58-65; DI STÉFANO, Roberto, El púlpito y la plaza: clero, sociedad y política de la monarquía católica a la república rosista, Buenos Aires, Siglo XXI editores Argentina, 2004, pp. 19-22; SERRANO, Sol, ¿Qué hacer con Dios en la República? Política y secularización en Chile (1845-1885), Santiago, Fondo de Cultura Económica, 2008, p. 20.

${ }^{4}$ Porfirio Díaz había conquistado el poder en 1876, bajo la premisa de la no reelección, un arma política para oponerse al régimen de su antecesor Sebastián Lerdo de Tejada. En aras de mantener su capital político, antes que reelegirse prefirió ceder la presidencia de la república a su compadre y antiguo compañero de 
En México, la república fue instaurada desde 1824. Tras el breve periodo monárquico de Maximiliano de Habsburgo entre 1864 y 1867 -conocido como el II Imperio-, la república se convirtió, a partir de este último año, en el único sistema político del país y aún permanece. La Constitución mexicana de 1857, que rigió hasta 1917, instituyó la libertad de cultos y, más tarde, las Leyes de Reforma de 1859 -elevadas a rango constitucional en 1874- establecieron la separación entre Iglesia y Estado, una de las primeras experiencias de separación del occidente católico. Los presidentes Porfirio Díaz (1876 - 1911), Francisco León de la Barra (1911) y Francisco I. Madero (1911 1913) compartían raíces liberales e hicieron de la defensa del Estado laico una de las premisas de sus administraciones. Díaz había sostenido que era católico "en privado y como cabeza de familia", pero "como jefe de Estado" no profesaba ninguna religión; Madero era ferviente espiritista, creencia que lo impulsó a iniciar la Revolución Mexicana en 19105. En Portugal, el 5 de octubre de 1910 los grupos antimonárquicos de Portugal tomaron las avenidas y el gobierno de las principales ciudades -entre ellas Lisboa-, dando paso a un proceso revolucionario marcado por la rapidez y la tranquilidad, por lo menos en sus primeros años, que llevó a la proclamación de la República Portuguesa, cuyas primeras medidas fueron la expulsión de los jesuitas y la expropiación de los bienes de las congregaciones religiosas ${ }^{6}$.

Las noticias sobre la república y la separación de Iglesia y Estado en Portugal llegaron a México cuando el régimen de Díaz enfrentaba el principio de la revolución. Mientras el gobierno de aquel país recibió información inmediata por parte de los diplomáticos acreditados, en la prensa el principal promotor de las noticias lusitanas, entre 1910 y 1913, fue Luis d'Arenas de Lima, el encargado portugués. A partir de esta documentación se realiza un análisis que además de contribuir a la historia de la lectura que se hizo de la Revolución de Portugal en el exterior durante los inicios de la república, pretende hacer un pequeño aporte a la historia de las relaciones bilaterales luso-mexicanas. En particular, se sostiene que la recepción -en los círculos diplomáticos y políticos de México-de la noticia de la separación de Iglesia y Estado en Portugal, ilustra la forma en que las repúblicas americanas, las cuales habían festejado en 1910 el primer centenario de su nacimiento, leyeron la formación de una república en Europa y, más aún, la formación de un Estado laico en la península ibérica. Desde esta perspectiva, este trabajo muestra un aspecto de las relaciones diplomáticas de México en los años del porfiriato y la Revolución Mexicana a partir de una relación prácticamente ignorada ${ }^{7}$. Del mismo modo, el trabajo contribuye a reflexionar acerca

armas, el General Manuel González, entre 1880 y 1884. Al volver a la presidencia de la república, afianzado ya en el poder, reformó la constitución de 1857 permitiendo varias reelecciones sucesivas.

${ }^{5}$ GARNER, Paul, Porfirio Díaz. Del héroe al dictador: una biografia política, México, Planeta, 2003, pp. 120-128; KRAUZE, Enrique, Mistico de la libertad. Francisco I. Madero, México, Fondo de Cultura Económica, 1987.

${ }^{6}$ RIBEIRO PINTO, Sérgio, Separaçao Religiosa como Modernidade. Decreto-Lei 20 de Abril de 1911 e modelos alternativos, Lisboa, Universidade Católica Portuguesa, 2011. CATROGA, Fernando, O Republicanismo em Portugal. Da formação ao 5 de Outobro, Lisboa, Editorial Noticias, 2000.

${ }^{7}$ A diferencia de lo que pasa con el otro país ibérico, España, cuya relación diplomática con México ha recibido una amplia atención por parte de los historiadores. Cf. MAC GREGOR, Josefina, Revolución y diplomacia: México y España 1913-1917, México, instituto Nacional de Estudios Históricos de la 
del impacto de los procesos de cambio político y anticlericalismo en las sociedades contemporáneas. En ese sentido, sigue la línea de José Ramón Rodríguez Lago, quien ha analizado cómo la Revolución en Portugal produjo en Galicia una guerra ideológica que enfrentó a los republicanos y liberales contra la jerarquía eclesiástica y los católicos militantes por la definición del modelo de sociedad española que ambos anhelaban durante el gobierno de Canalejas y la dictadura de Primo de Rivera ${ }^{8}$.

El artículo está dividido en dos apartados. En el primero se analiza la recepción diplomática y periodística en México de la declaración de la República Portuguesa. En el segundo, se presenta la reconstrucción de la lectura que los diplomáticos acreditados en ambos países hicieron de la separación Iglesia-Estado. Este artículo se basa en la documentación del Archivo Histórico del Ministerio de Negocios Extranjeros en Lisboa, el Archivo Histórico Genaro Estrada de la Secretaría de Relaciones Exteriores en México y en el archivo particular de Balbino Dávalos, resguardado en el Archivo Histórico Municipal de Colima, México. Las referencias bibliográficas fueron consultadas en la Hemeroteca Nacional de México y en la documentación que Arenas de Lima envió a Lisboa en sus reportes diplomáticos.

\section{La República Portuguesa en clave mexicana}

Las investigaciones pioneras de Fernando de Castro Brandão revelan una relación bilateral entre México y Portugal ciertamente visible en algunas ocasiones, pero intermitente y poco atendida por la reducida importancia cuantitativa de los contactos económicos y políticos entre ambas sociedades ${ }^{9}$. Si bien la relación con Portugal fue mucho menor a la que se tuvo con los demás países de la Europa occidental, como España, Francia e Inglaterra, su existencia es innegable, así como su importancia cualitativa. Más allá de los números, a partir de 1910 México se convirtió en un punto clave para relanzar la posición diplomática de Portugal en América. Cuando el 6 de enero de 1910 llegó a México Luis d'Arenas de Lima, miembro del servicio exterior lusitano y antiguo secretario de la legación en Washington, el propósito de la Corona portuguesa era iniciar desde aquel país el contacto con la recientemente independizada Cuba, el Caribe y Centroamérica, donde se esperaba poder obtener un nuevo mercado para los productos portugueses ${ }^{10}$. La presencia de Arenas de Lima en el país era un cambio importante en la relación bilateral: hasta entonces, las relaciones se habían mantenido a través de cónsules honorarios o con embajadores residentes en Washington. El Vizconde de Alte, encargado de negocios entre 1902

Revolución Mexicana, 2002; PI-SUÑER LLORENS, Antonia y SÁNCHEZ ANDRÉS, Agustín, Una historia de encuentros y desencuentros. México y España en el siglo XIX, México, Secretaría de Relaciones Exteriores, 2001.

${ }^{8}$ RODRÍGUEZ LAGO, José Ramón, La Iglesia Católica en Galicia (1910-1936). Entre la revolución de Portugal y la cruzada de España, Santiago de Compostela, Andavira editora, 2012, pp. 15-52.

${ }^{9}$ DE CASTRO BRANDAO, Fernando, Relações diplomáticas e consulares luso-mexicanas, Coimbra, s.e., 1981, p. 37. Hay traducción castellana: DE CASTRO BRANDAO, Fernando, Relaciones Diplomáticoconsulares entre México y Portugal, México, Secretaría de Relaciones Exteriores, 1982; ENRÍQUEZ PEREA, Alberto (compilación, introducción y notas), Daniel Cosío Villegas y su misión en Portugal, 19361937, México, El Colegio de México, Secretaría de Relaciones Exteriores, 1998.

${ }^{10}$ La Iberia, México, 8 de enero de 1910, p. 3. 
y 1912, apenas visitó tres veces el país: dos para presentar sus credenciales y una más como representante del Rey Manuel II en las fiestas del Centenario, en 1910. La apertura de este vínculo directo dio paso a un conocimiento más amplio de la realidad política y social de ambos países en un año que estaría marcado por el inicio de dos revoluciones: la primera, que produjo grandes cambios políticos, sociales y económicos en México; y la segunda, la de los Claveles en Portugal, que dio paso a la formación de la República Portuguesa vigente hasta ahora. Fue precisamente este momento el que abrió paso a una relación bilateral continua, que se canceló en 1913 ante la inestabilidad política que ocasionaba el estallido de violencia zapatista y la inestabilidad política en la península, lo que dio paso al retiro de los ministros y la suspensión de las relaciones bilaterales. A pesar de este temprano rompimiento, entre 1910 y 1913 la relación fue constante.

El periódico La Iberia escribió el ocho de enero de 1910: “[...] antes de ayer llegó a esta ciudad el Sr. D. Luis D’Arenas de Lima... quien trae la misión de estrechar más las relaciones de su país con el nuestro"11. Arenas era miembro permanente del servicio exterior lusitano, y se había desempeñado hasta entonces como secretario de la legación en Washington ${ }^{12}$.

La llegada de Arenas de Lima al país marca un punto coyuntural en la relación bilateral entre Portugal y México, pues fue la primera ocasión en que un diplomático portugués vivía en la ciudad de México. Hasta entonces, las relaciones, establecidas desde 1850, se habían mantenido a través de cónsules honorarios o con embajadores residentes en Washington. El Vizconde de Alte, encargado de negocios entre 1902 y 1912, apenas visitó tres veces el país: dos para presentar sus credenciales y una más como representante del Rey Manuel II en las fiestas del Centenario, en 1910. Arenas de Lima informó a Lisboa haber llegado a la ciudad de México el 5 de enero de este último año y haber tenido audiencia dos días después con el secretario de Relaciones Exteriores $^{13}$. Según se deja ver en su correspondencia, Arenas de Lima no solo tenía como objetivo fincar las relaciones bilaterales. Buscaba conocer mejor la realidad mexicana, fomentar el comercio portugués en México y Latinoamérica y, al mismo tiempo, acercarse diplomáticamente a los países centroamericanos y caribeños de habla española.

En correspondencia con la decisión lusitana, el gobierno mexicano nombró Encargado de negocios de México en Lisboa a Balbino Dávalos, diplomático y poeta, que también se desempeñaba como secretario de la Legación correspondiente en Estados Unidos. Dávalos llegó a Lisboa el 12 de marzo de 1910, procedente de Madrid ${ }^{14}$. Según le dijo personalmente Manuel II, “[...] el gobierno de Su Majestad deseaba mantener las mejores relaciones con el gobierno de un país tan próspero y floreciente

\footnotetext{
${ }^{11}$ La Iberia, México, 9 de enero de 1910, p. 1.

${ }^{12}$ DE CASTRO BRANDAO, Fernando, Relações diplomáticas e consulares luso-mexicanas, Coimbra, s.e., 1981, p. 37.

${ }^{13}$ AHD-MNE, caja 759, carpeta 1, f. 1.

${ }^{14}$ El Tiempo, México, 11 de abril de 1910, p. 2.
} 
Repúblicas laicas en Europa y América: la separación de la Iglesia y el Estado en Portugal...

como México"15. De modo que la misión de Arenas de Lima era establecer una representación oficial, buscar mejores condiciones comerciales en el país y mantener informado al gobierno mexicano de la situación política portuguesa.

La inestabilidad política se desencadenó en los dos países justo cuando se profundizaban las relaciones bilaterales. La correspondencia que Arenas de Lima envió al Ministerio de Negocios Extranjeros de Lisboa dio cuenta exacta de la revolución maderista entre 1910 y 1911. Así, por ejemplo, el 17 de diciembre de 1910 escribió que “[...] el candidato antirreleccionista, Señor [Francisco I.] Madero, pretendía oponerse a la reelección del Señor General Don Porfirio Díaz”, a pesar de que su labor “[...] era reconocida por todos los diplomáticos, y su robustez y agilidad a caballo, sea en ejercicios militares, sea en paseos, es muy admirada, y da muestras de su vigorosa salud" ". Arenas de Lima ofreció al gobierno portugués una descripción detallada de la Revolución Mexicana entre 1910 y $1913^{17}$.

Por su parte, Balbino Dávalos también informó con precisión los detalles que llevaron a la caída de la monarquía portuguesa. Fue gracias a la presencia de Dávalos en Lisboa que el gobierno mexicano, todavía en manos del presidente Porfirio Díaz, tuvo conocimiento de primera mano de los acontecimientos políticos de octubre en Portugal. A pesar de esta documentación -como ha señalado acertadamente Fernando de Castro Brandão- los acontecimientos políticos portugueses no tuvieron inmediata repercusión en México, pues había iniciado ya la Revolución Mexicana que llevaría a la caída de Díaz, al gobierno de Madero y, a partir de 1913, a una violencia generalizada en el territorio nacional ${ }^{18}$. Dávalos devino un informante sin mucho eco, pero mostró la postura ambivalente que los gobiernos mexicanos tuvieron ante la República Portuguesa: por una parte, aceptación de un régimen que gozaba de amplio consenso en su país de origen desde el siglo XIX, y por otro lado, rechazo a la posibilidad de violencia que traía consigo el cambio de régimen ${ }^{19}$.

\footnotetext{
${ }_{15}$ AHMC-FBD, caja 5, expediente 35, f. 1. "Correspondencia oficial de 1910-1912." Carta de Balbino Dávalos (en adelante, B.D.) al Secretario de Relaciones Exteriores, Lisboa, 12 de marzo de 1910.

${ }^{16}$ AHD-MNE, caja 760. "Registro dos officios para o Ministério dos Negócios Estrangeiros. Serie A, Livro 1", f. 5. Carta de Luis de Arenas de Lima al Ministro de Negocios Extranjeros, México, 17 de diciembre de 1910 .

${ }^{17}$ Las cartas en cuestión, conservadas en cuatro borradores en el Archivo del Ministério de Negocios Estrangeiros de Lisboa, cubren 42 meses, que corren entre enero de 1910 y julio de 1913. En conjunto, el material reúne 129 cartas, de las cuales las primeras 17 solo son resúmenes de la comunicación y las restantes 112, numeradas de la 18 a la 129, contienen el texto completo de la comunicación. En ellas informó al gobierno lusitano de la situación política de México y apuntó sus intentos por afianzar las relaciones diplomáticas en aquel país, en Centroamérica y en el Caribe.

${ }^{18}$ DE CASTRO BRANDAO, Fernando, Relações diplomáticas e consulares luso-mexicanas, Coimbra, s.e., 1981, p. 38.

${ }^{19}$ El consenso republicano se fraguó a lo largo del siglo XIX e incluso durante la Reforma liberal apenas fue debatido, a pesar del II Imperio, cuando se nombró emperador al Archiduque Austriaco Maximiliano de Habsburgo. Cf., PANI, Erika, Para mexicanizar el Segundo Imperio. El imaginario político de los imperialistas, México, El Colegio de México, Instituto Mora, 2001; HAMNETT, Brian, Juárez: el benemérito de las Américas, México, Colofón, 2006.
} 
En 1947, el antiguo encargado de negocios en Portugal publicó en el periódico Excélsior un texto biográfico, en el que recordaba los sucesos de los que fue testigo en Lisboa durante 1910. Según su testimonio, lo primero que lo consternó fue que la inestabilidad ocurriera en los dos países:

[...] en octubre, una revolución de tres días (del 4 al 6) derrumbó a la monarquía portuguesa y estableció la república, y a fines de noviembre recibía yo el primer aviso oficial de los disturbios que en México iniciaban la formidable revolución maderista que presto derrocaría al prolongadísimo Gobierno del General Díaz ${ }^{20}$.

Como muestran sus memorias, prestó mucha más atención a las lejanas noticias de México que a las que él mismo vivía en Lisboa. Para Dávalos 1911 fue un "año fatídico" por "[...] el triunfo de la revolución maderista y el colapso final de la época porfirista" ${ }^{21}$. Desafortunadamente, se enfocó más en lo ocurrido en su país que en el propio Portugal.

La noticia de la proclamación de la república llegó a la prensa mexicana de inmediato. Si bien todos los periódicos hicieron eco del suceso, The Mexican Herald, publicado en inglés e interesado en cuestiones internacionales, fue el que más atención otorgó a la caída de la monarquía. Además de señalar que "el líder republicano" Teófilo Braga era el "nuevo presidente", apuntaron que habían acontecido "duros enfrentamientos en las calles de Lisboa" y "el emblema de la monarquía en el palacio [había] sido remplazado por la bandera roja y verde, los colores del partido republicano". Arenas de Lima desacreditó de inmediato las noticias. Además, negó que el palacio real de Cintra hubiera sido bombardeado desde Lisboa, pues "sería como bombardear la casa del presidente Díaz en la calle de la Cadena desde Xochimilco". Atribuyó las noticias al trabajo de "agitadores españoles", que querían desacreditar a Portugal22.

La correspondencia que Balbino Dávalos envió a México al calor de los sucesos, revela claramente que, a pesar de interesarse en México, ofreció información valiosa y una mirada crítica a los sucesos portugueses. Entre el cinco y el seis de octubre de 1910 informó escuetamente sobre la revolución que, acompañada de bombardeos en la ciudad, había culminado con la proclamación de la República en Portugal. De inmediato recibió el permiso para salir de Lisboa si lo creía conveniente ${ }^{23}$. Se negó a partir, así lo manifestó en una de sus cartas: “[...] mi alejamiento [...] podría interpretarse como poco interés de nuestro gobierno por la transformación que en este país se está efectuando, o propósito de diferir la continuación de relaciones"24. Dávalos decidió ser un testigo ocular de los acontecimientos, y de esa manera ofreció al gobierno mexicano una lectura de primera mano sobre el cambio.

\footnotetext{
${ }^{20}$ DÁVALOS, Balbino, "Don Porfirio en el Ypiranga”, en Excélsior, México, 8 de julio de 1947, p. 7.

${ }^{21}$ Ibid.

${ }^{22}$ The Mexican Herald, México, 6 de julio de 1910, p. 2. Los textos están escritos en inglés. La traducción es del autor de este trabajo.

${ }^{23}$ AHMC-FBD, caja 5, exp. 35. "Correspondencia oficial de 1910-1912”. Carta B.D. al Secretario de Relaciones Exteriores, Lisboa, 6 de octubre de 1910, f. 149.

${ }^{24}$ Ibíd., Carta de B. D. al Secretario de Relaciones Exteriores (SRE), Lisboa, 14 de octubre de 1910, f. $173 \mathrm{v}$.
} 
Las cartas posteriores dieron más noticias acerca de su postura y la del gobierno mexicano; por ejemplo, el 14 de octubre de 1910 refiriéndose al estado del orden y la tranquilidad informa: "han continuado inalterables y todo induce a pensar que habrá de seguir así. Las adhesiones se suceden a diario; es curioso ver a viejos monarquistas y funcionarios declarándose republicanos de abolengo" y a los periódicos que hasta hace poco habían defendido al rey, "[...] de la noche a la mañana tornarse paladines del partido victorioso" 25 .

De este modo, la lectura negativa de una revolución que afectaba el statu quo presenciado por Dávalos desde su llegada en marzo, pronto se transformó en una visión mucho más positiva. Con la ausencia de la violencia, la República Portuguesa sería "un hermoso ejemplo ante el mundo", pues era un gobierno "[...] altamente intelectual, y establecido sin crueldades ni enconos, tan a poco costo" ${ }^{26}$. Después de una entrevista con el nuevo ministro de Negocios Extranjeros, Dávalos informó a México el 29 de octubre que la revolución había sido, desde la lectura del nuevo gobierno portugués, una "obra no de demolición sino de reforma". Además, señaló que la república era "una obra de redención [...] al fin iniciada [en Lisboa]". Pedía el reconocimiento mexicano, "[...] entre los pueblos [...] especie de sacramento nupcial que reclama decisión y [es] prueba de fraternidad y amor" ${ }^{27}$. Por otra parte, el seis de noviembre Machado visitó de nuevo a Dávalos y le pidió que hiciera saber al presidente Díaz: “[...] cuán grandes son la consideración y simpatía que este gobierno le consagra y cuán vivos son nuestros deseos por su bien personal y la prosperidad del país que tan bien gobierna"28. Al igual que el régimen porfiriano, el gobierno republicano de Portugal utilizó la nueva coincidencia de regímenes políticos como un argumento para estrechar relaciones bilaterales y, sobre todo, presionar por el reconocimiento oficial al nuevo gobierno.

La aceptación del régimen es un buen ejemplo de la forma en que el gobierno mexicano reaccionó ante la República Portuguesa. Desde el 14 de octubre, Dávalos informó que Brasil había entrado en relaciones oficiosas con la república y al día siguiente había hecho lo propio la Confederación Suiza. El 24 y 25 de octubre informó que las repúblicas brasileña y argentina reconocerían al régimen lusitano. Una semana más tarde Nicaragua y Uruguay también se mostraron de acuerdo, en estos países Portugal no tenía representaciones diplomáticas ${ }^{29}$. En una entrevista que Dávalos sostuvo con el ministro de Estados Unidos el 5 de noviembre, ambos señalaron que estaban a favor de la república, a pesar de no haber recibido órdenes para reconocerla ${ }^{30}$. El 14 de noviembre, finalmente, el diplomático mexicano informó que Inglaterra,

\footnotetext{
${ }^{25}$ Ibid., Carta de B. D. (SRE), 14 de octubre de 1910, f. 175.

${ }^{26}$ Ibid.

${ }^{27}$ Ibid., Carta de B. D. (SRE), 29 de octubre de 1910, f. 108.

${ }^{28}$ Ibid., Carta de B. D. (SRE), 6 de noviembre de 1910, f. 192.

${ }^{29}$ Ibíd., Carta de B. D. al Secretario de Relaciones Exteriores. Lisboa, 1 de noviembre de 1910, f. 192. A partir de 1911 y 1910, respectivamente, la relación lusitana con Latinoamérica se guiaba desde Argentina para América del Sur y desde México para Centroamérica y el Caribe hispanohablante.

${ }^{30}$ Ibid., Carta de B. D. (SRE), Lisboa, 5 de noviembre de 1910, f. 194.
} 
Francia, España, Alemania e Italia habían acordado entrar en relación con el gobierno republicano portugués; afirmó: "[...] la alegría y el entusiasmo han sido inmensos y se expresaron en la forma de una manifestación gigantesca" ${ }^{\text {"1 }}$. Desde noviembre, Dávalos insistía en que se debía otorgar el reconocimiento ${ }^{32}$, sin embargo, este se demoró ante el estallido de la Revolución Mexicana.

Según la carta que Dávalos envió a la Secretaría de Relaciones Exteriores el 17 de diciembre, la falta de reconocimiento al régimen, por parte de México, se atribuía en los círculos diplomáticos al "estado de revolución" del que había hablado la prensa, lo que perjudicaba para con muchos la autoridad del diplomático ${ }^{33}$. El 21 de enero de 1911 informó que la república era amenazada desde España, aun así señaló: “[...] persisto en creer bien imposible el fracaso del nuevo régimen, y más improbable todavía la restauración de la casa de Braganza"34. En el mismo tenor, el 30 de mayo de 1911, sostuvo que había en Portugal, o por lo menos en Lisboa,

[...] grandes entusiasmos populares por la república, adhesión de muchos monárquicos a las nuevas instituciones; empeño y trabajo por parte de las autoridades; confianza en el comercio y restablecimiento de la tranquilidad pública [...] sigo creyendo que es más fácil la consolidación de la república que la posibilidad de una contrarrevolución ${ }^{35}$.

El 7 de junio de 1911 Dávalos señaló, ya con impaciencia, que era “indispensable proceder al reconocimiento del país", pues hasta Estados Unidos se preparaba para hacerlo $^{36}$. Si se hacía muy tarde, México perdería una buena oportunidad para poner en alto su imagen en Portugal. En este contexto, el 22 de junio Bernardino Machado informó directamente a la Cancillería mexicana que se había proclamado la República en Portugal, cuando ya era presidente de la república mexicana el antiguo Secretario de Relaciones Exteriores Francisco León de la Barra ${ }^{37}$. Cuatro días después, Dávalos informó que ya había irritación en Lisboa por la falta de reconocimiento ${ }^{38}$. Fue entonces cuando se procedió a la petición. El 28 de junio Arenas de Lima telegrafió a Lisboa informando que el Gobierno mexicano reconocería en unos días "la república democrática" como forma de gobierno en Portugal ${ }^{39}$. Balbino Dávalos concretó el reconocimiento de México a la república portuguesa el 5 de julio de $1911^{40}$.

\footnotetext{
${ }^{31}$ Ibid., Cartas de B. D. (SRE), Lisboa, 11 y 16 de noviembre de 1910, f. 203-204.

32 Ibid., Carta de B. D. (SRE), Lisboa, 5 de noviembre de 1910, f. 194.

${ }^{33}$ Ibid., Carta de B. D. (SRE), Lisboa, 17 de diciembre de 1910, f. 246.

${ }^{34}$ Ibid., Carta de B. D. (SRE), Lisboa, 21 de enero de 1910, f. 273.

${ }^{35}$ Ibid., Carta de B. D. (SRE), Lisboa, 30 de mayo de 1911, f. 317.

${ }^{36}$ Ibid., Carta de B. D. (SRE), Lisboa, 7 de junio de 1911, f. 327.

${ }^{37}$ AHGE-SRE, 42-27-6.

${ }^{38}$ Ibid., Carta de B. D. al Secretario de Relaciones Exteriores. Lisboa, 26 de junio de 1911, f. 346.

${ }^{39}$ AHD, caja 760. "Registro dos Officios para o Ministério dos Negócios Estrangeiros. Serie A, Livro 2". f. 10. Oficio de Luis de Arenas de Lima al Ministro de Negocios Extranjeros, México, 1 de julio de 1911. El texto original está escrito en portugués. La traducción de la breve cita textual es del autor de este trabajo.

${ }^{40}$ AHMC-FBD, Carta de B. D. al Secretario de Relaciones Exteriores. Lisboa, 5 de julio de 1911, f. 355.
} 
En síntesis, el representante mexicano en Lisboa y el gobierno mexicano mostraron simpatía por la república, máxime cuando se percataron que era una "revolución de caballeros", según epíteto que transmitió Dávalos al régimen de Díaz ${ }^{41}$. A través de la importancia que Dávalos concedió a las pláticas con el ministro Machado, es palpable que creía que el régimen republicano implementaría una reforma social que debía garantizar el éxito económico, el valor más apreciado por la generación que acompañó a Díaz en el poder. Sin embargo, la Revolución Mexicana, que estalló en noviembre de 1910, impidió que la noticia se difundiera con mayor atención en la prensa de aquel país y, al mismo tiempo, dificultó que el gobierno mexicano otorgara el reconocimiento a la república. Este llegó en la presidencia de Francisco León de la Barra, en julio de 1911.

Es de ponderarse la postura no solo de México, sino de las repúblicas latinoamericanas. Al contrario que las monarquías europeas, los países americanos apoyaron decisivamente a la República Portuguesa desde octubre de 1910. Así, las repúblicas americanas, que en 1910 cumplían 100 años de existencia, apoyaron bien pronto la instauración de un régimen como el suyo. En México hacía 50 años que se había decretado la separación entre Iglesia y Estado. Ahora bien, ¿cómo reaccionaron el enviado y el gobierno mexicano ante la ley de separación portuguesa entre Iglesia y Estado, decretada en 1911? Ello se abordará en el siguiente apartado.

\section{La separación portuguesa vista desde una república laica}

Al mismo tiempo que informaba sobre la proclamación de la república lusitana, The Mexican Herald pidió a Luis de Arenas de Lima noticias sobre la política de su país. Según informó el encargado de negocios, en Portugal había tres partidos: los clericales, los monarquistas y los republicanos, estos últimos eran minoría en la cámara de representantes. Si bien los monarquistas y los republicanos estaban unidos en contra del clero, el rey utilizaba su poder para contener el anticlericalismo y así mantener la unidad del país ${ }^{42}$.

Esta noticia de Arenas de Lima, un día después de la proclamación de la república, es una de las pocas referencias directas a las cuestiones religiosas en Portugal en la primera hora del cambio de régimen. En una carta a Balbino Dávalos fechada el cuatro de noviembre de 1910, el ministro de educación de México Justo Sierra se lamentaba de que se informara muy poco en los periódicos sobre los sucesos políticos lusitanos $\mathrm{y}$, en general, sobre "todas esas cosas de Portugal con que soñamos". Por ello pidió al encargado de negocios, viejo amigo suyo, que le informara al respecto ${ }^{43}$. A pesar de esta petición, Dávalos tampoco prestó mucha atención a las relaciones entre Iglesia y Estado en Portugal. Hubo dos motivos para ello, el más inmediato y fortuito fue que el encargado de negocios mexicano salió de Portugal entre el 21 de febrero y el primero

\footnotetext{
${ }^{41}$ Ibid., Carta de B. D. al Secretario de Relaciones Exteriores. Lisboa, 7 de diciembre de 1910, f. $235 \mathrm{v}$.

${ }^{42}$ The Mexican Herald, México, 6 de julio de 1910, p. 2.

${ }^{43}$ Carta de Justo Sierra a Balbino Dávalos, México, 4 de noviembre de 1910, en SIERRA, Justo, Obras completas, volumen XIV, Epistolario y papeles privados, México, Universidad Nacional Autónoma de México, 1991, pp. 495-496. (Nueva Biblioteca Mexicana, 62).
} 
de mayo de 1911, para enviar a su hijo a un colegio suizo y cuidar en Madrid la edición de las obras de Ignacio Mariscal, el secretario de Relaciones Exteriores de México recién fallecido ${ }^{44}$. Otra razón más profunda radica en que el Estado mexicano era laico desde 1859 y su constitución anticlerical desde 1857, por consiguiente, los problemas eclesiásticos de otros países no formaban parte de la agenda diplomática mexicana.

Incluso el contacto oficial de diplomáticos mexicanos con jerarcas eclesiásticos debía ser sopesado. El 31 de marzo de 1910, después de visitar al rey Manuel II, Dávalos visitó al Nuncio del papa en Portugal, Giulio Tonti, pues era el "jefe y cabeza de toda la representación extranjera en Portugal", y la cortesía "era inevitable" ${ }^{45}$. Al día siguiente recibió el pago de la visita del Nuncio, quien llegó "revestido de su traje cardenalicio". Tras varios titubeos, decidió “[...] omitir toda información a México, para evitar cualquier intempestiva ligereza"46. De modo que la lectura que se hizo en México sobre la ley de separación portuguesa fue escueta y quedó marcada por la condición laica de la república americana. Asimismo, como en el caso de la proclamación de la república, Dávalos prestó mayor interés a los sucesos mexicanos, lo que distrajo su atención de los acontecimientos políticos lusitanos. E1 27 de mayo, unos días después de volver a Lisboa, se le informó que León de la Barra asumiría la presidencia ${ }^{47}$. A pesar de lo anterior, ¿cómo se leyó la separación portuguesa en México? En términos generales, se consideró que era parte del proceso de instauración de la república, del fortalecimiento del nuevo régimen y, más aún, un escalón necesario en el camino del país hacia el progreso.

Además de la importancia de la república y la laicidad en México, esta lectura positiva de la separación portuguesa tenía sus raíces en la formación intelectual de la clase política mexicana. Como muchos otros letrados mexicanos, el mismo Balbino Dávalos llegó de su ciudad natal, Colima, a la capital del país en 1881, donde encontró que la enseñanza del positivismo era impulsada por el gobierno de Díaz. Como ha mostrado Charles Hale, en México el liberalismo dio paso al positivismo durante la segunda mitad del siglo XIX, como parte del proceso de consolidación del Estado liberal laico ${ }^{48}$.

Entre los intelectuales con los que Dávalos se relacionó estuvo Justo Sierra -quien llegaría a ser ministro de Educación en México y el principal promotor del positivismo

\footnotetext{
${ }^{44}$ AHMC-FBD, Carta de B. D. al Secretario de Relaciones Exteriores. Lisboa, 19 de febrero de 1911, f. 284.

${ }^{45}$ Giulio Tonti nació en Roma, en cuyo seminario pontificio obtuvo los doctorados de filosofía, teología, derecho civil y cánones. En 1879 fue nombrado oficial de la Sagrada Congregación de Asuntos Eclesiásticos Extraordinarios. Inició sus labores diplomáticas como auditor de las nunciaturas de Francia y Portugal entre 1879 y 1892 . En 1892 lo designaron delegado apostólico en Haití y Venezuela. Ese mismo año fue elevado al rango de arzobispo titular de Samos por León XIII. En 1902 Tonti fue nombrado nuncio en Brasil y cuatro años más tarde en Portugal, puesto al que renunció tras la revolución en 1910. Fue nombrado cardenal por Benedicto XV en 1914 y, posteriormente, prefecto de la Sagrada Congregación de los Religiosos, en este último cargo murió en diciembre de 1918.

${ }^{46}$ DÁVALOS, Balbino, "Don Porfirio en el Ypiranga”, en Excélsior, México, 8 de julio de 1947.

${ }^{47}$ AHMC-FBD, Carta de B. D. (SRE), Lisboa, 27 de mayo de 1911, f. 313.

${ }^{48}$ HALE, Charles A., The transformation of liberalism in late Nineteenth-century Mexico.
} 
Repúblicas laicas en Europa y América: la separación de la Iglesia y el Estado en Portugal...

spenceriano en el país- con el que mantuvo una relación personal el resto de su vida ${ }^{49}$. Sierra retomó de Spencer y aplicó al positivismo mexicano dos conceptos: la libertad como ideal y el evolucionismo. A su vez, Sierra consideró que la ciencia era el camino para transformar a México, darle paz, orden, progreso y libertad. Este fue el ideal del gobierno de Porfirio Díaz.

Gracias a la publicación de Evolución política del pueblo mexicano, en 1900, Sierra fue uno de los pilares de la historiografía mexicana y uno de los promotores de una lectura laica de la historia de México. En su libro, Sierra aborda la relación entre Iglesia y Estado al ocuparse de la Reforma mexicana (1855-1867). Según él, uno de los ejes del proceso fue la separación entre ambas potestades, un movimiento animado por la defensa de las libertades que la civilización había hecho necesarias: la libertad de pensar y la libertad de $\operatorname{creer}^{50}$. De hecho, la Reforma mexicana es vista como una lucha religiosa en la que se enfrentaron curas y militares contra abogados patriotas. En síntesis, a partir de dicha Reforma Justo Sierra consideró que la Patria era la república ${ }^{51}$. Así, la separación Iglesia-Estado quedó identificada al amanecer del siglo XX con los intereses nacionales y el progreso spenceriano de las sociedades.

En México, el propio régimen de Díaz era visto desde esta perspectiva. La guía de su política, como en Lerdo e Iglesias, eran los "dogmas liberales":

[...] la separación de la Iglesia y el Estado; la supresión de las comunidades religiosas como asociaciones absolutamente ilegales; la prohibición de adquirir bienes raíces a todas las corporaciones, y las consecuencias de todo esto en el estado civil de las personas, en las manifestaciones externas del culto ${ }^{52}$.

Pero Díaz fue más allá e instauró la paz, de esta creó las comunicaciones, la industria y la riqueza. Así pues, Sierra unificó la república con el laicismo y el progreso económico. En esta lectura histórica y en la unificación de república, laicidad y progreso se entiende la interpretación que Dávalos y el gobierno de México hicieron de la ley de separación portuguesa.

Debido a que Dávalos había estado en España entre marzo y abril, su lectura sobre la laicidad del Estado en Portugal quedó ligada a la postura monárquica del presidente del gobierno español, José Canalejas, con quien se entrevistó en Madrid. En sus juicios de valor, Dávalos muestra la preferencia mexicana por la república; el encargado de negocios olvidó referir que Canalejas era un destacado liberal. Informó a México que durante su estancia en España, las noticias en torno a una revolución violenta en Portugal eran una constante, dado el matiz anticlerical que había tomado la

\footnotetext{
${ }^{49}$ ZEA, Leopoldo, El positivismo en México: nacimiento, apogeo y decadencia, México, Fondo de Cultura Económica, 2005, p. 304.

${ }^{50}$ SIERRA, Justo, Evolución política del pueblo mexicano, México, Consejo Nacional para la Cultura y las Artes, 1993, pp. 278-283.

${ }^{51}$ Ibid., p. 232.

${ }^{52}$ Ibid., p. 385.
} 
república ${ }^{53}$. En la misma carta refirió su entrevista con Canalejas, el español rechazaba la República Portuguesa: con "la campaña de prensa que están haciéndome, tratan de agitarme a los republicanos, y eso no lo puedo tolerar" 54 .

La primera referencia directa sobre la separación portuguesa que Balbino Dávalos envió a México tenía como marco las elecciones de mayo de 1911. Los republicanos habían conseguido "un triunfo absoluto" y, además, había faltado "por completo el elemento monárquico", mostrando así la fortaleza del nuevo régimen ${ }^{55}$. Dávalos describió desde su perspectiva la situación del clero y la jerarquía eclesiástica en Portugal, así lo sostuvo en una carta el 30 de mayo: "[...] los jesuitas desterrados y el alto clero [...] se han esforzado y aún continúan esforzándose por organizar a todo trance la contrarrevolución. Pero todo lo ha hecho fracasar hasta ahora la actividad del gobierno provisorio" ${ }^{56}$. En suma, para Dávalos el clero era el más importante de los “elementos conservadores" de la sociedad portuguesa, que buscaba volver por sus privilegios de inmediato ${ }^{57}$. De manera que la separación Iglesia-Estado fue vista por el encargado de negocios mexicano como parte de la secularización de la sociedad portuguesa; esta disociación, contribuyó al fortalecimiento y la consolidación de la nueva república.

Una semana más tarde, el 7 de junio, Dávalos sostuvo que los conspiradores monárquicos y clericales seguían sus trabajos “[...] activamente dentro del país como en la frontera española"58. El presidente Porfirio Díaz, quien acababa de renunciar a la presidencia de México, llegó a Vigo en junio de 1911. Dávalos fue a recibirlo. Esto dio pie para que el ministro Machado manifestara al mexicano que Díaz era un ejemplo para el nuevo régimen, pues había conseguido hacer de la república mexicana un modelo de orden y progreso económico, gracias a la fortaleza del gobierno y a su buen sustento jurídico, entre sus logros destacaba la separación Iglesia-Estado ${ }^{59}$. Si bien no parece ser un modelo definitorio, los hombres fuertes del nuevo régimen portugués tenían presente el ejemplo de la república laica mexicana y consideraban que esta era -o podía ser- un modelo plausible para proceder a la implementación de la laicidad en el Estado portugués.

En perspectiva similar, un curioso incidente en México mostró que si bien las sociedades de ambos países eran mayoritariamente católicas, sus gobiernos se

\footnotetext{
${ }^{53}$ La identificación de la república con el anticlericalismo era casi axiomática en España, donde se debatía la libertad de cultos como uno de los elementos centrales de la agenda republicana. En la década de 1930 la "cuestión religiosa" fue uno de los aspectos de mayor debate. Cf. CASTAÑEDA DELGADO, Paulino y GARCÍA DE LOMAS MIER, José María (Coords.), La Iglesia y la II República. Actas del XVIII simposio de historia de la Iglesia en España y América, Córdoba, CajaSur, 2009. (Colección Estudios. Actas).

${ }^{54}$ Entre las pocas publicaciones que circularon en México sobre la caída de la monarquía estuvo el libro de VIVERO, Augusto y DE LA VILLA, Antonio, Cómo cae un trono (la revolución en Portugal). Impresiones de Benito Pérez Galdós, Teófilo Braga, Guerra Junqueiro, Bernardino Machado y França Borges, Madrid, Biblioteca Renacimiento, 1910. La postura era republicana.

${ }^{55}$ AHMC-FBD, Carta de B. D. (SRE), Lisboa, 30 de mayo de 1911, f. 316.

${ }^{56}$ Ibid., Carta de B. D. al Secretario de Relaciones Exteriores, Lisboa, 30 de mayo de 1911, f. 321.

${ }^{57}$ Ibid.

${ }^{58}$ Ibíd., Carta de B. D. (SRE), Lisboa, 7 de junio de 1911, f. 327

${ }^{59}$ DÁVALOS, Balbino, "Don Porfirio en el Ypiranga”, en Excélsior, 8 de julio de 1947, p. 7.
} 
mostraban vigilantes del clero. En julio y agosto de 1910, el obispo Henrique José Reed da Silva, antiguo prelado territorial de Mozambique, obispo de Santo Tomás de Meliapore y en aquel tiempo obispo titular de Trajanópolis en Frigia, visitó México. Arenas de Lima informó a Lisboa y esta instruyó a Dávalos para que hiciera saber al gobierno mexicano que Reed había "colgado los hábitos, se había visto envuelto en escándalos, y carecía de posición en este país”. Además, era un hombre peligroso por estar "[...] lleno de atractivos personales, [ser] muy cautivador e insinuante, afortunado galanteador de damas y de carácter muy jovial". La información se hizo llegar, pues el gobierno lusitano "no querría que el gobierno amigo [fuese] a resentir algún inconveniente de un obispo portugués" ${ }^{60}$. Así se evitó que el presidente recibiera al mitrado como se había proyectado para mejorar las relaciones con Portugal. Arenas de Lima dejó claro que las atenciones a Su Majestad Fidelísima no pasaban por concesiones a los obispos y que el presidente Díaz podía seguir con la costumbre mexicana de no recibir oficialmente a los eclesiásticos en eventos públicos, y menos revestidos episcopalmente ${ }^{61}$.

El gobierno republicano portugués se interesó en particular por la situación de la Iglesia en México. El nueve de diciembre de 1911 el doctor Augusto de Vasconcelos, nuevo ministro de Negocios Extranjeros, pidió a Arenas de Lima información sobre la Iglesia en México y, en particular, sobre la influencia que los portugueses tenían en ella. Además de constatar que ni siquiera la devoción de San Antonio de Padua tenía antecedentes portugueses, Arenas de Lima insistió en mostrar una imagen de separación: los obispos, que vivían tranquilos en sus palacios, evitaban salir de los templos revestidos sacerdotalmente y no solían recibir visitas oficiales, sino "enteramente particulares", como la que él mismo había realizado ${ }^{62}$. Esta actitud era un modelo a seguir para el gobierno portugués.

En el mismo tenor, la correspondencia de Balbino Dávalos muestra que si bien no había relaciones oficiales con los jerarcas católicos mexicanos, la elite intelectual mexicana sí tenía contacto con diversos obispos en el país. Siguiendo una pauta establecida desde 1867, cuando la Iglesia mexicana renunció a la participación política, varios de ellos se dedicaban, junto con sus labores episcopales, a tareas literarias ${ }^{63}$. Así, durante su estancia en Lisboa Dávalos tuvo correspondencia privada con el obispo de Veracruz, Joaquín Arcadio Pagaza, con el de San Luis Potosí, Ignacio Montes de Oca, e incluso con el arzobispo portugués de Calcedonia in partibus infidelium, Antonio Ayres da Gouvea. En los tres casos las cartas se ocupan de cuestiones estrictamente literarias ${ }^{64}$.

\footnotetext{
${ }^{60}$ AHMC-FBD, Carta de B. D. al Secretario de Relaciones Exteriores, Lisboa, 5 de agosto de 1910, f. 121.

${ }^{61}$ AHD-MNE, caja 759. Carta de Luis d'Arenas de Lima al Consejero Eduardo Villaça, ministro dos Negócios Estrangéiros, México, 7 de mayo de 1910, f. 1.

${ }^{62}$ AHD-MNE, caja 760. "Registro dos officios para o Ministério dos Negócios Estrangeiros, Serie A, Livro No. 3", ff. 11-11v.

${ }^{63}$ ADAME GODDARD, Jorge, El pensamiento político y social de los católicos mexicanos, 1867-1914, México, Instituto Mexicano de Doctrina Social Cristiana, 1991.

${ }^{64}$ AHMC-FBD, caja 3, exps. 69 y 81; caja 5, exp. 12.
} 
De vuelta a su labor oficial en Lisboa, Dávalos ofreció una última lectura sobre la separación, a partir de la oposición entre España y Portugal. El 22 de junio de 1911 comunicó a México que tras entrevistarse con el representante español, este le informó: “[...] para España, este pueblo [el portugués] con sus nuevas instituciones es ya un peligro para su monarquía; le está promoviendo una política intolerable" Entre las más grandes preocupaciones españolas estaban, según denunciaba Dávalos, la separación entre Iglesia y Estado. Si se llegara al enfrentamiento, el resultado sería desastroso para Portugal y para las instituciones que poco a poco se iban consolidando.

A partir de entonces, Dávalos se interesó mucho más por la Revolución Mexicana que por la consolidación de la república y la separación en Portugal. Lo mismo hizo en México Luis de Arenas de Lima. El gobierno de Madero interesado en la pacificación del país y en el mantenimiento del orden, compartía la matriz liberal y, por tanto, el consenso en los beneficios de la república laica. Resuelta esta cuestión, la agenda mexicana prestó mucha más atención a los asuntos internos que a los problemas religiosos de Portugal.

\section{Conclusiones}

El gobierno y la prensa de México recibieron positivamente la proclamación de la república y la ley de separación Iglesia-Estado en Portugal. A pesar de esta abierta simpatía, en un primer momento la respuesta mexicana ante la proclamación republicana fue ambivalente. Si bien es cierto que el régimen de Porfirio Díaz y el mismo Balbino Dávalos vieron al nuevo régimen lusitano como "un ejemplo para el mundo", también es evidente que temieron y rechazaron la posible violencia que entrañaba la caída de la Monarquía Fidelísima. No era para menos en un país que a partir de noviembre de 1910 viviría su propia revolución que se extendería a lo largo de la década y cuya primera consecuencia sería, precisamente, la caída del régimen de Díaz.

Es preciso señalar que la respuesta de la cancillería mexicana a los acontecimientos portugueses estuvo condicionada por la Revolución Mexicana que, entre 1910 y 1911, produjo la caída del presidente Porfirio Díaz, el ascenso al poder de Francisco León de la Barra y Francisco I. Madero y, lentamente, despertó la violencia entre los grupos campesinos, situación que preocupó especialmente a Arenas de Lima. Ante ello, las noticias en torno a Portugal y sus rápidos pasos hacia la secularización social perdieron importancia en México. A pesar de esto, la coincidencia de regímenes fue un argumento para estrechar relaciones bilaterales, así como un arma de Portugal para obtener el reconocimiento de México. De hecho, el reconocimiento que las repúblicas latinoamericanas dieron al nuevo régimen lusitano coadyuvó al fortalecimiento de la República Portuguesa.

En lo que concierne a la recepción de la ley de separación de la Iglesia y el Estado en Portugal, esta fue apoyada por las elites liberales mexicanas, que habían

${ }^{65}$ Ibid., caja 5, exp. 35. Carta de B. D. (SRE), Lisboa, 22 de junio de 1911, ff. 341-344. 
hecho de su credo un consenso y un mito unificador de la nación ${ }^{66}$. Después de la Reforma liberal, el modelo de independencia entre Iglesia y Estado decretado por Benito Juárez en 1859 había permitido que la laicidad del Estado fuera una base fundamental del régimen político mexicano. Para Balbino Dávalos e intelectuales como el entonces ministro de educación Justo Sierra, la separación entre Iglesia y Estado era un "dogma liberal" -como lo llamó Sierra-, al igual que la supresión de comunidades religiosas y el fin del culto externo; aspectos que aplicaron los liberales republicanos lusitanos en 1911. En ese sentido, la elite gobernante y liberal de México saludó los cambios del Portugal republicano como muestra de que el modelo de república laica podía funcionar en Europa. De hecho, la larga experiencia laica de México, que declaró la separación de ambas potestades en 1859, fue un ejemplo de laicidad considerado por los hombres de la República Portuguesa.

A partir de una relación bilateral prácticamente ignorada por la historiografía, este trabajo quiere llamar la atención acerca de dos aspectos que trascienden este estudio de caso. En primer lugar, la importancia de considerar los procesos de laicidad en Europa y América como momentos de afirmación de un nuevo modelo de Estado que sin ser antirreligioso insistía en la necesidad de constituirse como un garante de la libertad de consciencia. Desde esta perspectiva, las elites liberales construían elementos jurídicos que permitían afianzar la legitimidad del Estado en la defensa de la libertad de sus ciudadanos, quienes eran considerados individuos libres e iguales en el marco jurídico republicano. Al hacerlo, afianzaban una nueva base de legitimidad y soberanía para el poder civil, desplazando la religión a la esfera de lo privado. Al explorar la recepción en México de la separación de la Iglesia y el Estado en Portugal, se buscó enfatizar en lo novedoso y temprano que fue el modelo mexicano de independencia entre ambas potestades. Implementado en 1859, el modelo de república laica mexicana pudo ser conocido y discutido por los liberales lusitanos a inicios del siglo XX. El caso mexicano fue incluso anterior a la laicidad francesa, implementada en 1905. De manera que, valdría la pena repasar experiencias americanas y considerar el impacto que los modelos republicanos del Nuevo Mundo tuvieron en Europa; temas que suelen ser considerados solo en el sentido inverso.

La revisión del caso portugués hace plausible sostener que el modelo de repúblicas americanas laicas fue conocido y reconocido por los republicanos europeos como un instrumento válido para afianzar la posición republicana en sus respectivas sociedades. Proyectos de separación similares, por ejemplo, ocurrieron en Colombia, entre 1853 y 1885, y en Guatemala a partir de 1871 bajo el régimen de Justo Rufino Barrios. Sirva el caso analizado como una invitación para explorar la incidencia de estas experiencias en los proyectos liberales europeos de la época. Un segundo aspecto, que vale la pena destacar, es la necesidad de plantear problemáticas que permitan comprender procesos que superan las fronteras nacionales. En este caso

\footnotetext{
${ }^{66}$ Un ejemplo de los mecanismos para afianzar este proceso después de la Reforma por parte de la elite liberal puede verse en JIMÉNEZ MARCE, Rogelio, "La creación de una genealogía liberal", en Historias, No. 51, 2002, pp. 27-49.
} 
se ha dado mayor énfasis a la laicidad, pero queda por explorar la simultaneidad de procesos en diversos países de Europa y América. Hacer historias desde las fronteras implica en ocasiones superar las fronteras y comprender los procesos desde una óptica global.

Al centrase en la laicidad y en las relaciones luso-mexicanas, el análisis enfatizó en la lectura que los mexicanos hicieron de la separación de Iglesia y Estado en Portugal. En consecuencia, es preciso insistir que, para los políticos y los intelectuales mexicanos, el decreto de abril de 1911 fue parte de la consolidación de la República portuguesa y un paso necesario en el camino hacia el progreso social. En un sentido más amplio, fue un paso importante hacia la secularización social a partir de la laicidad jurídica implementada en la nueva república. Del mismo modo, gracias al consenso que los mexicanos concedían al trinomio república, laicidad y progreso, la disociación de Iglesia y Estado en Portugal fue considerada en México como un acto positivo y necesario. La simpatía de México hacia la república y la separación se construyó en el fortalecimiento de los vínculos bilaterales, así como en la afinidad que los cambios lusitanos de 1910 y 1911 despertaron en un país que, allende el mar, era laico y republicano como el nuevo Portugal.

\section{Fuentes}

\section{Fuentes primarias}

\section{Archivos}

Archivo Histórico Diplomático - Ministerio de Negocios Estrangeiros (AHD-MNE), Lisboa.

Archivo Histórico "Genaro Estrada" - Secretaría de Relaciones Exteriores (AHGESER), México.

Archivo Histórico del Municipio de Colima - Fondo Balbino Dávalos (AHMC-FBD), Colima.

\section{Publicaciones periódicas}

La Iberia, México, 1910.

The Mexican Herald, México, 1910.

El Tiempo, México, 1910.

\section{Documentación primaria impresa}

DÁVALOS, Balbino, "Don Porfirio en el Ypiranga", en Excélsior, México, 8 de julio de 1947.

SIERRA, Justo, Evolución politica del pueblo mexicano, México, Consejo Nacional para la Cultura y las Artes, 1993.

SIERRA, Justo, Obras completas, volumen XIV, Epistolario y papeles privados, México, Universidad Nacional Autónoma de México, 1991 (Nueva Biblioteca 
Repúblicas laicas en Europa y América: la separación de la Iglesia y el Estado en Portugal...

Mexicana, 62).

VIVERO, Augusto y DE LA VILLA, Antonio, Cómo cae un trono (la revolución en Portugal). Impresiones de Benito Pérez Galdós, Teófilo Braga, Guerra Junqueiro, Bernardino Machado y França Borges, Madrid, Biblioteca Renacimiento, 1910.

\section{Fuentes secundarias}

\section{Libros}

ADAME GODDARD, Jorge, El pensamiento político y social de los católicos mexicanos, 1867-1914, México, Instituto Mexicano de Doctrina Social Cristiana, 1991.

BLANCARTE, Roberto, Laicidad en México, México, Universidad Nacional Autónoma de México, Cátedra Extraordinaria Benito Juárez, Instituto de Investigaciones Jurídicas, 2013.

CASTAÑEDA DELGADO, Paulino y GARCÍA DE LOMAS MIER, José María (coords.), La Iglesia y la II República. Actas del XVIII simposio de historia de la Iglesia en España y América, Córdoba, CajaSur, 2009. (Colección Estudios. Actas).

CATROGA, Fernando, O Republicanismo em Portugal. Da formação ao 5 de Outobro, Lisboa, Editorial Noticias, 2000.

DE CASTRO BRANDAO, Fernando, Relações diplomáticas e consulares lusomexicanas, Coimbra, s.e., 1981.

DE CASTRO BRANDAO, Fernando, Relaciones Diplomático-consulares entre México y Portugal, México, Secretaría de Relaciones Exteriores, 1982.

DI STÉFANO, Roberto, El púlpito y la plaza: clero, sociedad y política de la monarquía católica a la república rosista, Buenos Aires, Siglo XXI editores Argentina, 2004.

ENRÍQUEZ PEREA, Alberto (compilación, introducción y notas), Daniel Cosío Villegas y su misión en Portugal, 1936-1937, México, El Colegio de México, Secretaría de Relaciones Exteriores, 1998.

GARNER, Paul, Porfirio Díaz. Del héroe al dictador: una biografía política, México, Planeta, 2003.

HALE, Charles A., The transformation of liberalism in late Nineteenth-century Mexico, Princeton, Princeton University Press, 1989.

HAMNETT, Brian, Juárez: el benemérito de las Américas, México, Colofón, 2006. 
KRAUZE, Enrique, Místico de la libertad. Francisco I. Madero, México, Fondo de Cultura Económica, 1987.

MAC GREGOR, Josefina, Revolución y diplomacia: México y España 1913-1917, México, instituto Nacional de Estudios Históricos de la Revolución Mexicana, 2002.

MATOS FERREIRA, António, Um católico militante diante da crise nacional. Manuel Isaías Abúndio da Silva (1874-1914), Lisboa, Universidade Católica Portuguesa, Centro de Estudos de História Religiosa, 2007.

PANI, Erika, Para mexicanizar el Segundo Imperio. El imaginario político de los imperialistas, México, El Colegio de México, Instituto Mora, 2001.

PI-SUÑER LLORENS, Antonia y SÁNCHEZ ANDRÉS, Agustín, Una historia de encuentros y desencuentros. México y España en el siglo XIX, México, Secretaría de Relaciones Exteriores, 2001.

POULAT, Émile, Liberté, laicieté: la guerre des deux France et le principe de la modernité, Paris, Les Éditions du Cerf, Editions Cujas, 1987.

POULAT, Émile, La solution laique et ses problemes: Fausses certitudes, vrais inconnues, Paris, Berg International Editeurs, 1999.

RIBEIRO PINTO, Sérgio, Separaçao Religiosa como Modernidade. Decreto-Lei 20 de Abril de 1911 e modelos alternativos, Lisboa, Universidade Católica Portuguesa, 2011.

RODRÍGUEZ LAGO, José Ramón, La Iglesia Católica en Galicia (1910-1936). Entre la revolución de Portugal y la cruzada de España, Santiago de Compostela, Andavira editora, 2012.

SERRANO, Sol, ¿Qué hacer con Dios en la República? Política y secularización en Chile (1845-1885), Santiago, Fondo de Cultura Económica, 2008.

ZEA, Leopoldo, El positivismo en México: nacimiento, apogeo y decadencia, México, Fondo de Cultura Económica, 2005.

\section{Capítulos de libro}

BARBOSA DELGADO, Francisco Roberto, "El principio de laicidad en la educación en Francia y en el tribunal Europeo de Derechos Humanos: entre el universalismo francés y el reconocimiento al margen nacional de apreciación del TEDH", en Oasis, No. 16, 2011, pp. 39-58.

DE ROUX, Rodolfo, "Las etapas de la laicización en Colombia”, en BASTIAN, JeanPierre (Coord.), La modernidad religiosa. Europa y América latina en perspectiva 
Repúblicas laicas en Europa y América: la separación de la Iglesia y el Estado en Portugal...

comparada, México, Fondo de Cultura Económica, 2004, pp. 61-73.

MALLIMACI, Fortunato, "Catolicismo y liberalismo: las etapas del enfrentamiento por la definición de la modernidad religiosa en América Latina”, en BASTIAN, JeanPierre (Coord.), La modernidad religiosa. Europa y América latina en perspectiva comparada, México, Fondo de Cultura Económica, 2004, pp. 19-44.

MATOS FERREIRA, Antonio, "Laicidade", en MOREIRA AZEVEDO, Carlos (Dir.), Diccionário de História Religiosa de Portugal, Lisboa, Círculo de Leitores, 2001, pp. 58-65.

\section{Artículos}

JIMÉNEZ MARCE, Rogelio, "La creación de una genealogía liberal”, en Historias, No. 51, 2002, pp. 27-49. 